\title{
A Simple and Efficient MPPT Method for Low-Power PV Cells
}

\author{
Maria Teresa Penella ${ }^{1}$ and Manel Gasulla ${ }^{2}$ \\ ${ }^{1}$ Urbiotica S.L, Parc UPC, Edifici Nexus II, C/Jordi Girona 29, 08034 Barcelona, Spain \\ ${ }^{2}$ Universitat Politècnica de Catalunya, C/Esteve Terradas 7, 08860 Castelldefels, Spain \\ Correspondence should be addressed to Manel Gasulla; manel.gasulla@upc.edu
}

Received 31 October 2013; Accepted 28 December 2013; Published 27 February 2014

Academic Editor: Ismail H. Altas

Copyright (C) 2014 M. T. Penella and M. Gasulla. This is an open access article distributed under the Creative Commons Attribution License, which permits unrestricted use, distribution, and reproduction in any medium, provided the original work is properly cited.

Small-size PV cells have been used to power sensor nodes. These devices present limited computing resources and so low complexity methods have been used in order to extract the maximum power from the PV cells. Among them, the fractional open circuit voltage (FOCV) method has been widely proposed, where the maximum power point of the PV cell is estimated from a fraction of its open circuit voltage. Here, we show a generalization of the FOCV method that keeps its inherent simplicity and improves the tracking efficiency. First, a single-diode model for PV cells was used to compute the tracking efficiency versus irradiance. Computations were carried out for different values of the parameters involved in the PV cell model. The proposed approach clearly outperformed the FOCV method, specially at low irradiance, which is significant for powering sensor nodes. Experimental tests performed with a $500 \mathrm{~mW}$ PV panel agreed with these results.

\section{Introduction}

The advances in electronics and communication protocols have led to a widespread use of wireless sensor networks (WSN). In most applications, the sensor nodes of the WSN are required to be wireless both for communication and powering. As for the power supply, the use of small-size PV cells or modules has been proposed. The power-voltage $(\mathrm{P}-\mathrm{V})$ curve of a photovoltaic (PV) cell or panel presents a maximum power point (MPP) that changes with temperature and irradiance. To extract the maximum power under varying conditions an MPP tracker can be used. Several MPP tracking (MPPT) methods have been proposed in the literature [1-4]. Since sensor nodes present limited computing resources, low complexity MPPT methods are preferred for this particular application. Because the location of the sensor nodes is mostly determined by the application, a wide range of irradiance can be expected at the sensor placement. Thus, a high efficiency is desirable over a wide range of irradiance, and specially for low irradiance as the power source is scarce.

One of the simplest and most popular MPPT methods is the fractional open circuit voltage (FOCV) technique, which estimates the MPP voltage $\left(V_{\mathrm{MPP}}\right)$ from a fraction of the open circuit voltage $\left(V_{\mathrm{OC}}\right)$; that is,

$$
V_{\mathrm{MPP}, \text { est }}=k V_{\mathrm{OC}} \text {, }
$$

where $V_{\text {MPP,est }}$ is the estimated value of the actual $V_{\text {MPP }}$ and $k$ is an empirical constant whose value should be set following a thorough characterization of the PV panel under varying meteorological conditions (irradiance and cell temperature). $V_{\mathrm{OC}}$ is either measured periodically (by momentarily opening the output of the PV panel) or by using a pilot cell (i.e., an additional solar cell of the same type configured in open circuit voltage configuration). Typical reported values for $k$ range from 0.73 to 0.8 depending on the PV panel type and characteristics $[2,3]$. Because of its simplicity, the FOCV method has been recently applied to small-size PV cells in order to power autonomous sensors [5-9].

In this work, we propose to generalize (1) in order to estimate $V_{\mathrm{MPP}}$ by using a linear fit; that is,

$$
V_{\mathrm{MPP}, \text { est }}=a V_{\mathrm{OC}}+b \text {, }
$$

where $a$ and $b$ are empirical coefficients. The use of (2) will be referred to as the linear open circuit voltage (LOCV) 
method. In fact, the FOCV method can be considered a particular case of the proposed LOCV method with $b=0$. Both computed and experimental results of the proposed approach will be presented and compared with the FOCV method. As will be shown, the LOCV method significantly improves the performance of the FOCV method, especially at low irradiance, while maintaining its inherent simplicity. The work presented here builds upon [10], where we first presented (2) and some initial results.

\section{Solar Cell Model}

Different equivalent circuits have been used in the literature in order to model the current/voltage $(I-V)$ characteristic of a silicon PV cell [11-15]. Among them, the single-diode model, shown in Figure 1, offers a good compromise between simplicity and accuracy [13], whereby $I_{\mathrm{PH}}$ is the photogenerated current, $I$ is the cell current, $V$ is the cell voltage, and $R_{\mathrm{s}}$ and $R_{\mathrm{p}}$ are, respectively, the series and shunt resistances. This model will be used here in order to generate computed data of the $I-V$ curve of a PV cell.

The corresponding expression of the $I-V$ characteristic is given by [16]

$$
I=I_{\mathrm{SC}}-I_{\mathrm{O}}\left[e^{\left(\left(q\left(V+R_{\mathrm{s}} I\right)\right) / n_{\mathrm{d}} K T_{\text {cell }}\right)}-1\right]-\frac{V+R_{\mathrm{s}} I}{R_{\mathrm{p}}},
$$

where $I_{\mathrm{PH}}$ has been approximated by $I_{\mathrm{SC}}$, the short circuit current of the cell; $I_{\mathrm{O}}$ is the saturation current of the diode; $q$ is the electron charge; $n_{\mathrm{d}}$ is the ideality factor of the diode, which, for silicon, is usually between 1 and $2[5,7] ; K$ is the Boltzmann constant; and $T_{\text {cell }}$ is the cell temperature in Kelvin.

By considering open circuit conditions $(I=0$ and $V=$ $\left.V_{\mathrm{OC}}\right)$ in (3), we can write the parameter $I_{\mathrm{O}}$ as

$$
I_{\mathrm{O}}=\frac{I_{\mathrm{SC}}-\left(V_{\mathrm{OC}} / R_{\mathrm{p}}\right)}{\left[e^{\left(q V_{\mathrm{OC}} / n_{\mathrm{d}} K T_{\text {cell }}\right)}-1\right]} .
$$

The parameters $I_{\mathrm{SC}}$ and $V_{\mathrm{OC}}$ in (3) and (4) change with the irradiance and temperature as

$$
\begin{aligned}
I_{\mathrm{SC}}\left(T_{\text {cell }}, G\right) & =\frac{G}{1000}\left[I_{\mathrm{SC}_{\mathrm{r}}}+\alpha\left(T_{\text {cell }}-T_{\mathrm{r}}\right)\right], \\
V_{\mathrm{OC}}\left(T_{\text {cell }}, G\right)= & {\left[V_{\mathrm{OC}_{\mathrm{r}}}+\beta\left(T_{\text {cell }}-T_{\mathrm{r}}\right)\right] } \\
\times & {\left[1+\rho_{\mathrm{OC}} \ln \left(\frac{G}{G_{\mathrm{OC}}}\right) \ln \left(\frac{G}{G_{\mathrm{r}}}\right)\right], }
\end{aligned}
$$

where $T_{\text {cell }}$ is the cell temperature; $G$ is the incident irradiance (in $\mathrm{W} / \mathrm{m}^{2}$ ); $\alpha$ and $\beta$ are the current and voltage temperature coefficients, respectively; $I_{\mathrm{SC}_{r}}$ and $V_{\mathrm{OC}_{\mathrm{r}}}$ are given at a reference irradiance $\left(G_{\mathrm{r}}\right)$ and reference cell temperature $\left(T_{\mathrm{r}}\right)$; and $\rho_{\mathrm{OC}}$ and $G_{\mathrm{OC}}$ are two empirical constants used to model the significant variation of $V_{\mathrm{OC}}$ at low $G$. Typically, $G_{\mathrm{r}}=$ $1000 \mathrm{~W} / \mathrm{m}^{2}\left(=100 \mathrm{~mW} / \mathrm{cm}^{2}\right)$ and $T_{\mathrm{r}}=25^{\circ} \mathrm{C}$. Values of $\rho_{\mathrm{OC}}=$ -0.04 and $G_{\mathrm{OC}}=1000 \mathrm{~W} / \mathrm{m}^{2}$ are adequate for many silicon PV cells [17]. When directly illuminated, solar cells heat up

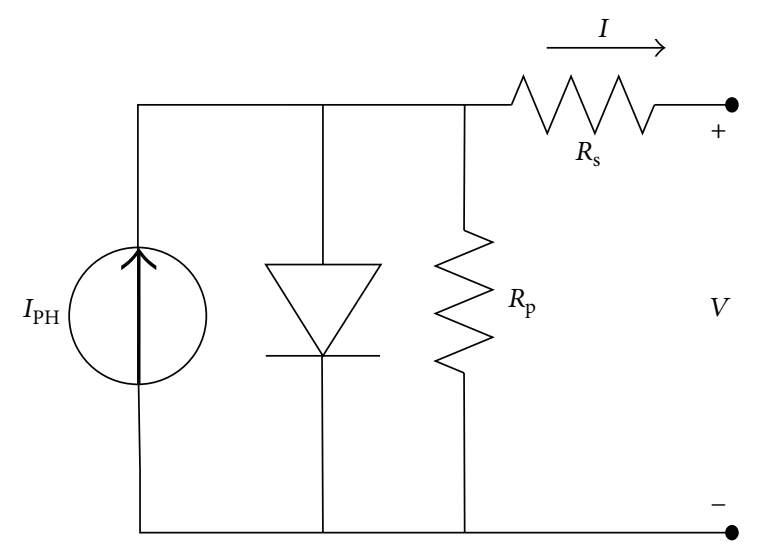

FIgURE 1: Single-diode model of a solar cell with series $\left(R_{\mathrm{s}}\right)$ and shunt $\left(R_{\mathrm{p}}\right)$ resistances.

above the ambient temperature $\left(T_{\mathrm{a}}\right)$, which is known as the self-heating effect, and $T_{\text {cell }}$ can be obtained from

$$
T_{\text {cell }}=T_{\mathrm{a}}+\frac{T_{\text {cell,NOCT }}-20}{800 \mathrm{~W} / \mathrm{m}^{2}} G .
$$

where $T_{\text {cell,NOCT }}$, known as the nominal operating cell temperature (NOCT), is the temperature of the cell when exposed to $800 \mathrm{~W} / \mathrm{m}^{2}$ at $T_{\mathrm{a}}=20^{\circ} \mathrm{C}$ and wind speed of $1 \mathrm{~m} / \mathrm{s}$. It is empirically determined, and for silicon solar cells range between $42^{\circ} \mathrm{C}$ and $48^{\circ} \mathrm{C}$.

\section{Computed Results}

We employed (3) to (7) with the following parameter values typical of monocrystalline solar cells [17]: $J_{\mathrm{SC}_{\mathrm{r}}}=35 \mathrm{~mA} / \mathrm{cm}^{2}$; $V_{\mathrm{OC}_{\mathrm{r}}}=0.6 \mathrm{~V} ; \alpha / A=12.5 \mu \mathrm{A} / \mathrm{cm}^{2} /{ }^{\circ} \mathrm{C} ; \beta=-2 \mathrm{mV} /{ }^{\circ} \mathrm{C}$; and $T_{\text {cell,NOCT }}=42^{\circ} \mathrm{C}$. The parameters $I_{\mathrm{SC}_{\mathrm{r}}}$ and $\alpha$ in (5) can be, respectively, obtained by multiplying $J_{\mathrm{SC}_{\mathrm{r}}}$ and $\alpha / A$ by the area of the cell. For the computations, a single solar cell with an area of $1 \mathrm{~cm}^{2}$ was used. Nevertheless, as will be justified at the end of this section, the results and the derived conclusions are equally valid to cells of any area and PV panels composed of an arbitrary number of solar cells disposed in parallel and series. Figure 2 shows the computed $I-V$ and $P-V$ curves at three different levels of irradiance for the particular case of $R_{\mathrm{s}}=0, R_{\mathrm{p}}=\infty, n_{\mathrm{d}}=1.5$, and $T_{\mathrm{a}}=25^{\circ} \mathrm{C}$. To obtain the data we simulated the PV cell model in SPICE. The power values were obtained by multiplying $I$ by $V$ at each data point. As can be seen, both $V_{\mathrm{OC}}$ and $V_{\mathrm{MPP}}$ slightly decrease at the highest irradiance, which is due to the self-heating effect of the PV cell.

From the data of the $I-V$ and $P-V$ curves, several parameters can be obtained such as $V_{\mathrm{OC}}, V_{\mathrm{MPP}}$, and $P_{\mathrm{MPP}}$ (power at the MPP). Table 1 shows numerical values of those parameters for an irradiance range from $c a .20 \mathrm{~W} / \mathrm{m}^{2}$ to $1000 \mathrm{~W} / \mathrm{m}^{2}$. Fourteen points of irradiance, logarithmically equally spaced, were selected to provide a dynamic range around 100 in $P_{\mathrm{MPp}}$. Other cases that will be discussed throughout this section are also shown in Table 1. Figure 3 
TABLE 1: Computed $V_{\mathrm{OC}}, V_{\mathrm{MPP}}$; and $P_{\mathrm{MPP}}$ data at fourteen points of irradiance, logarithmically equally spaced, and for different values of the parameters of the PV cell model.

\begin{tabular}{|c|c|c|c|c|c|c|c|c|c|c|c|c|c|c|c|}
\hline \multirow{2}{*}{$\begin{array}{l}G \\
\left(\mathrm{~W} / \mathrm{m}^{2}\right)\end{array}$} & \multicolumn{3}{|c|}{$n_{\mathrm{d}}=1.5($ Figure 1$)$} & \multicolumn{3}{|c|}{$n_{\mathrm{d}}=1$} & \multicolumn{3}{|c|}{$n_{\mathrm{d}}=2$} & \multicolumn{3}{|c|}{$r_{\mathrm{s}}=0.1$ (Figure 6$)$} & \multicolumn{3}{|c|}{$r_{\mathrm{p}}=10($ Figure 8$)$} \\
\hline & $\begin{array}{c}V_{\mathrm{OC}} \\
(\mathrm{V})\end{array}$ & $\begin{array}{c}V_{\mathrm{MPP}} \\
(\mathrm{V})\end{array}$ & $\begin{array}{l}P_{\mathrm{MPP}} \\
(\mathrm{mW})\end{array}$ & $\begin{array}{c}V_{\mathrm{OC}} \\
(\mathrm{V})\end{array}$ & $\begin{array}{c}V_{\mathrm{MPP}} \\
(\mathrm{V})\end{array}$ & $\begin{array}{l}P_{\mathrm{MPP}} \\
(\mathrm{mW})\end{array}$ & $\begin{array}{c}V_{\mathrm{OC}} \\
(\mathrm{V})\end{array}$ & $\begin{array}{c}V_{\mathrm{MPP}} \\
(\mathrm{V})\end{array}$ & $\begin{array}{l}P_{\mathrm{MPP}} \\
(\mathrm{mW})\end{array}$ & $\begin{array}{c}V_{\mathrm{OC}} \\
(\mathrm{V})\end{array}$ & $\begin{array}{c}V_{\mathrm{MPP}} \\
(\mathrm{V})\end{array}$ & $\begin{array}{l}P_{\mathrm{MPP}} \\
(\mathrm{mW})\end{array}$ & $\begin{array}{c}V_{\mathrm{OC}} \\
(\mathrm{V})\end{array}$ & $\begin{array}{c}V_{\mathrm{MPP}} \\
(\mathrm{V})\end{array}$ & $\begin{array}{l}P_{\mathrm{MPP}} \\
(\mathrm{mW})\end{array}$ \\
\hline 23.7 & 0.262 & 0.194 & 0.135 & 0.262 & 0.207 & & 0.262 & 0.185 & & 0.262 & 0.193 & 0.134 & & & \\
\hline 31.6 & 0.311 & 0.237 & 0.227 & .311 & 0.251 & 0.254 & 0.311 & 0.226 & 0.205 & 0.311 & 0.235 & 0.225 & & & \\
\hline 42.2 & 0.357 & 0.277 & 0.362 & 0.357 & 0.293 & 0.401 & 0.357 & 0.264 & 0.330 & 0.357 & 0.275 & 0.359 & 0.241 & 0.126 & 0.095 \\
\hline 56.2 & 0.398 & 0.313 & 0.553 & & 0.331 & & & 0.300 & & 0.398 & 0.311 & & 0.306 & 0.168 & 0.168 \\
\hline 75 & 0.434 & 0.347 & 0.826 & 0.434 & 0.365 & 0.904 & 0.434 & 0.332 & & 0.434 & 0.343 & & 0.369 & 0.221 & 0.299 \\
\hline 100 & 0.467 & 0.376 & 1.2 & 0.467 & 0.396 & 1.312 & 0.467 & 0.361 & 1.113 & 0.467 & 0.372 & 1.186 & 0.42 & 0.282 & 0.524 \\
\hline 133.4 & 0.495 & 0.402 & 1.725 & 0.495 & 0.422 & 1.874 & 0.495 & 0.385 & 1.60 & 0.495 & 0.395 & 1.693 & 0.462 & 0.337 & 0.899 \\
\hline 177.8 & 0.518 & 0.423 & 2.431 & 0.518 & 0.444 & 2.635 & 0.518 & 0.406 & 2.259 & 0.518 & 0.415 & 2.374 & 0.494 & 0.379 & 1.477 \\
\hline 237.1 & 0.537 & 0.440 & 3.38 & 0.537 & 0.461 & 3.657 & 0.537 & 0.422 & 3.146 & 0.537 & 0.429 & 3.279 & 0.519 & 0.409 & 2.321 \\
\hline 316.2 & 0.55 & 0.452 & 4.64 & & 0.474 & & & 0.434 & & 0.55 & 0.437 & 4.458 & 0.537 & 0.43 & 3.500 \\
\hline 421.7 & 0.558 & 0.458 & 6.28 & 0.558 & 0.481 & 6.786 & 0.558 & 0.441 & 5.853 & 0.558 & 0.439 & 5.961 & 0.548 & 0.443 & 5.094 \\
\hline 562.3 & 0.56 & 0.459 & 8.386 & 0.56 & 0.482 & 9.067 & 0.56 & 0.441 & 7.812 & 0.56 & 0.433 & 7.821 & 0.553 & 0.448 & 7.185 \\
\hline 749.9 & 0.555 & 0.454 & 11.031 & 0.555 & 0.477 & 11.943 & 0.555 & 0.436 & 10.264 & 0.555 & 0.42 & 10.035 & 0.55 & 0.446 & 9.850 \\
\hline 1000 & 0.543 & 0.442 & 14.254 & 0.543 & 0.464 & 15.472 & 0.543 & 0.424 & 13.234 & 0.543 & 0.398 & 12.511 & 0.54 & 0.436 & 13.13 \\
\hline
\end{tabular}

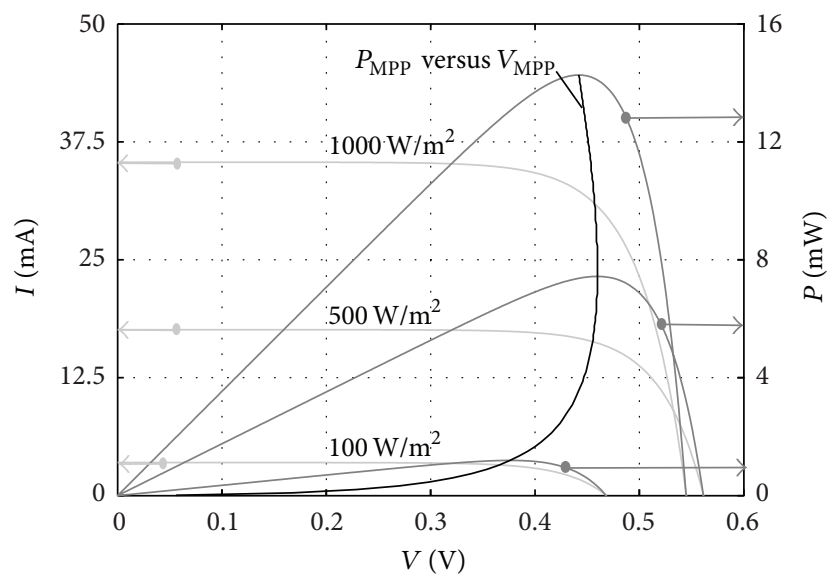

Figure 2: Generic $I-V$ and $P-V$ plots at several values of $G$ and at $T_{\mathrm{a}}=25^{\circ} \mathrm{C}$ for a single solar cell with an area of $1 \mathrm{~cm}^{2}$. A curve joining the MPPs is also plotted.

represents the fourteen computed points (diamonds) of $V_{\mathrm{MPP}}$ versus $V_{\mathrm{OC}}$ and two least-squares regression lines fitted to the computed data corresponding, respectively, to the FOCV method, that is, (1) with $k=0.809$, and the LOCV method, that is, (2) with $a=0.894$ and $b=-0.041$. As can be seen, the regression line corresponding to the LOCV method better fits the computed data. The inferred parameters of the regression lines $(k, a$, and $b)$ were used to obtain $V_{\mathrm{MPP} \text {,est }}$ at the fourteen irradiance points for each of the two methods, by using (1) and (2), respectively.

The corresponding power values at $V_{\mathrm{MPP}, \text { est }}, P_{\mathrm{MPP}, \text { est }}$ were inferred from the computed $P$ - $V$ curves in order to obtain the tracking efficiency, which is given by

$$
\eta_{\mathrm{MPP}}=\frac{P_{\mathrm{MPP}, \text { est }}}{P_{\mathrm{MPP}}}
$$

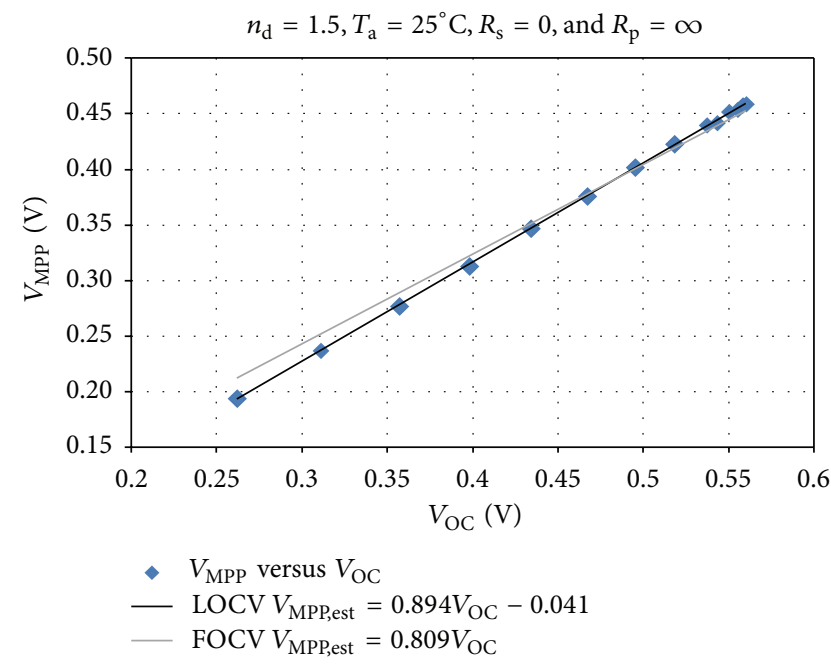

Figure 3: Computed $V_{\text {MPP }}$ versus $V_{\text {OC }}$ for a single PV cell. Two least-square regression lines are also represented: the grey line corresponds to the FOCV method with $k=0.809$ whereas the black line corresponds to the LOCV method with $a=0.894$ and $b=-0.041$. The parameters of the PV cell model are $T_{\mathrm{a}}=25^{\circ} \mathrm{C}$, $n_{\mathrm{d}}=1.5, R_{\mathrm{s}}=0$, and $R_{\mathrm{p}}=\infty$.

This parameter is used in the literature to compare the performance among different algorithms. Obviously, a value of $1(100 \%)$ is the ultimate goal. Figure 4 shows the computed values of $\eta_{\text {MPPT }}$ versus $G$ at $T_{\mathrm{a}}=25^{\circ} \mathrm{C}$ for the fourteen irradiance points. We added the results at two more temperatures, $0^{\circ} \mathrm{C}$ and $50^{\circ} \mathrm{C}$. For these temperatures, the $P-V$ curves were recalculated but we still used the same regression lines of Figure 3. This makes sense, as a PV panel can be characterized at a single temperature, for example, $25^{\circ} \mathrm{C}$, and the calculated regression lines used for 


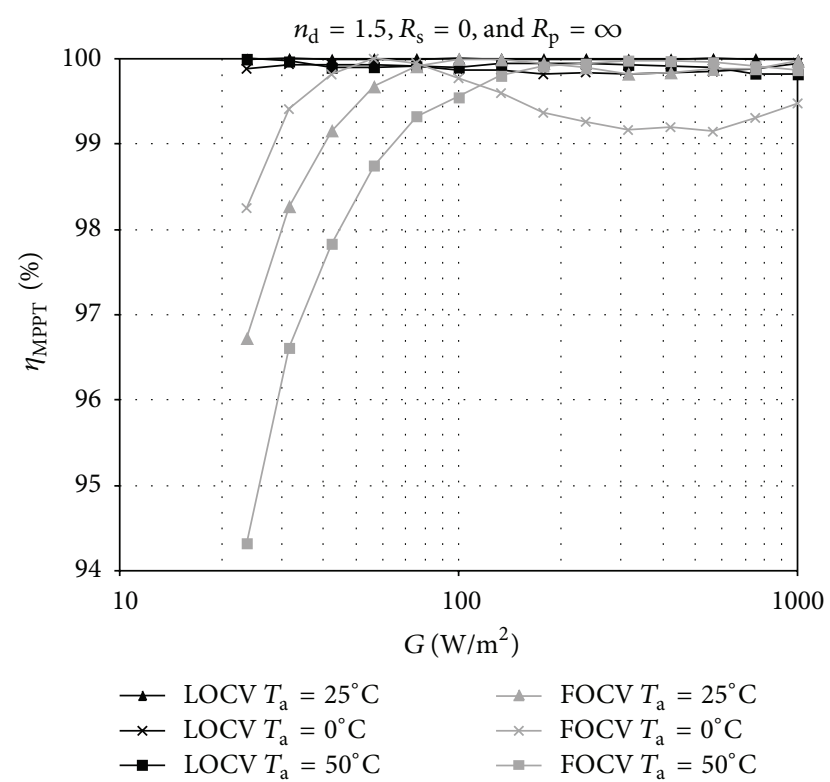

FIGURE 4: Computed $\eta_{\text {MPPT }}$ versus $G$ by using the FOCV and LOCV methods for a single PV cell at different values of $T_{\mathrm{a}}$ and with $n_{\mathrm{d}}=$ $1.5, R_{\mathrm{s}}=0$, and $R_{\mathrm{p}}=\infty$.

the full working temperature range. As can be seen, at low irradiance the LOCV method clearly outperforms the FOCV method. At higher irradiance, a rather high value of $\eta_{\mathrm{MPPT}}$ (>99\%) is achieved by both methods, although the FOCV method presents the lowest efficiency from $c a .100 \mathrm{~W} / \mathrm{m}^{2}$ to $1000 \mathrm{~W} / \mathrm{m}^{2}$ at $T_{\mathrm{a}}=0{ }^{\circ} \mathrm{C}$. The value of $\eta_{\mathrm{MPPT}}$ for the LOCV method was always higher than $99.8 \%$ at the three computed temperatures.

More computations were carried out at $T_{\mathrm{a}}=25^{\circ} \mathrm{C}$ for $n_{\mathrm{d}}=1$ and $n_{\mathrm{d}}=2$ (see Table 1). Again, better linear fits were obtained with the LOCV method (not shown). Figure 5 shows the corresponding computed values of $\eta_{\mathrm{MPPT}}$. For each of the cases, the parameters of the corresponding regression lines are provided. Again, the LOCV method clearly outperforms the FOCV method at low irradiance and slightly at medium irradiance.

Finally, computations were performed for $n_{\mathrm{d}}=1.5, T_{\mathrm{a}}=$ $25^{\circ} \mathrm{C}$, nonzero values of $R_{\mathrm{s}}$, and finite values of $R_{\mathrm{p}}$. In [13] normalized values for $R_{\mathrm{s}}$ and $R_{\mathrm{p}}$ were defined as

$$
\begin{aligned}
& r_{\mathrm{s}}=\frac{R_{\mathrm{s}}}{\left[V_{\mathrm{OC}} / I_{\mathrm{SC}}\right]_{\mathrm{STC}}}, \\
& r_{\mathrm{p}}=\frac{R_{\mathrm{p}}}{\left[V_{\mathrm{OC}} / I_{\mathrm{SC}}\right]_{\mathrm{STC}}} .
\end{aligned}
$$

This normalization allows for an immediate comparison among different PV modules (of different area and characteristics). Based on [13], in our work we considered the following values: from 0.01 to 0.1 for $r_{\mathrm{s}}$ and from 100 to 10 for $r_{\mathrm{p}}$. The performance for both $r_{\mathrm{s}}=0.01$ and $r_{\mathrm{p}}=100$ was almost identical to that shown in Figure 2 (for $T_{\mathrm{a}}=25^{\circ} \mathrm{C}$ ), with the LOCV method outperforming the FOCV method. So these

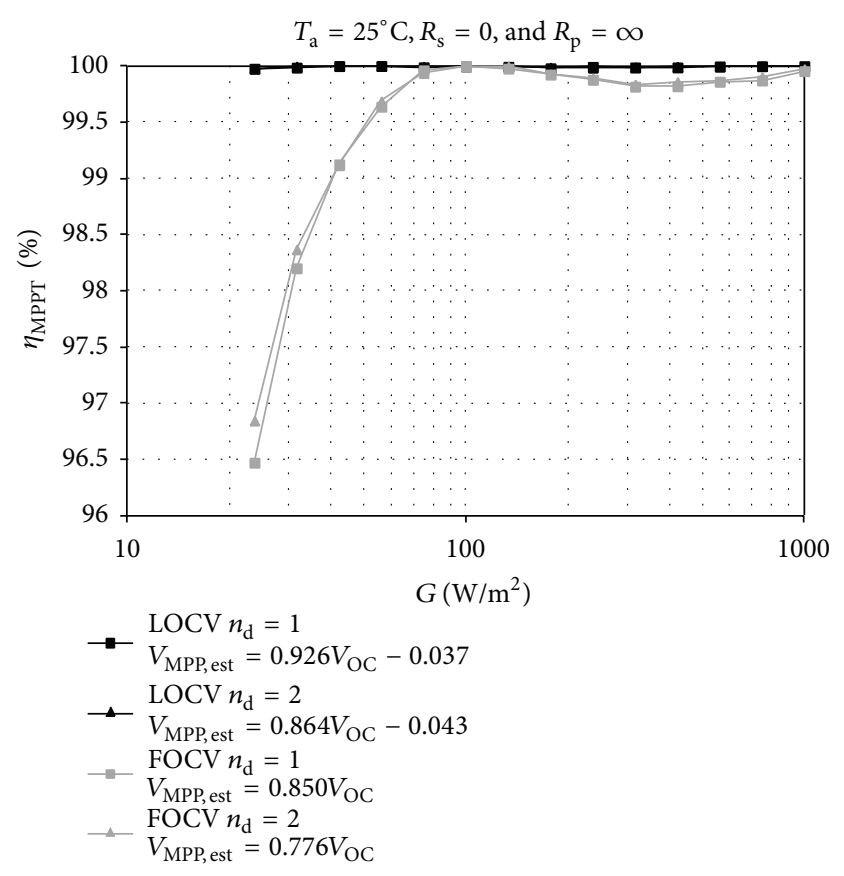

FIGURE 5: Computed $\eta_{\text {MPPT }}$ versus $G$ by using the FOCV and LOCV methods for a single PV cell at different values of $n_{\mathrm{d}}$ and with $T_{\mathrm{a}}=$ $25^{\circ} \mathrm{C}, R_{\mathrm{s}}=0$, and $R_{\mathrm{p}}=\infty$.

results are not shown here. Table 1 shows the data for the limiting cases $r_{\mathrm{s}}=0.1$ (with $r_{\mathrm{p}}=\infty$ ) and $r_{\mathrm{p}}=10$ (with $r_{\mathrm{s}}=0$ ). For the case of $r_{\mathrm{p}}=10$, the data for the lowest two irradiance levels were not used as they provided negligible values of $P_{\text {MPP }}$ (well below of $1 \%$ of the resulting $P_{\text {MPP }}$ at $1000 \mathrm{~W} / \mathrm{m}^{2}$ ). As for $r_{\mathrm{s}}=0.1$, Figure 6 shows the computed values of $V_{\text {MPP }}$ versus $V_{\text {OC }}$ and the fitted regression lines. Due to the high value of $r_{s}$ (highest limit), the data values present a folded form at the highest irradiance levels. So the regression lines of the FOCV and LOCV methods cannot fit the data corresponding to the high irradiance levels as well as that in Figure 3. Otherwise, both lines are very similar in this case. Consequently, the computed values of $\eta_{\mathrm{MPPT}}$, shown in Figure $7\left(r_{\mathrm{s}}=0.1\right)$, are quite similar (and indeed relatively high) for both methods.

As for $r_{\mathrm{p}}=10$, Figure 8 again shows the computed values of $V_{\mathrm{MPP}}$ versus $V_{\mathrm{OC}}$ and the fitted regression lines. Due to the low relative value of $r_{\mathrm{p}}$ (lowest limit) the regression line of the LOCV method cannot fit the data corresponding to the low irradiance levels as well as that in Figure 3. Even so, the computed values of $\eta_{\text {MPPT }}$, also shown in Figure 7 , still present a high efficiency, outperforming the FOCV method at all the irradiance levels, but specially at the low ones. Finally, we computed $\eta_{\mathrm{MPPT}}$ for $r_{\mathrm{s}}=0.1$ and $r_{\mathrm{p}}=10$ (not shown). In that case, the LOCV method also outperformed the FOCV method at low and medium irradiance levels.

Increasing the PV cell area or adding identical PV cells in parallel will scale up the values of currents and thus of powers but the values of $V_{\mathrm{OC}}$ and $V_{\mathrm{MPP}}$ will remain the same and so the derived tracking efficiencies. Tracking efficency will also 


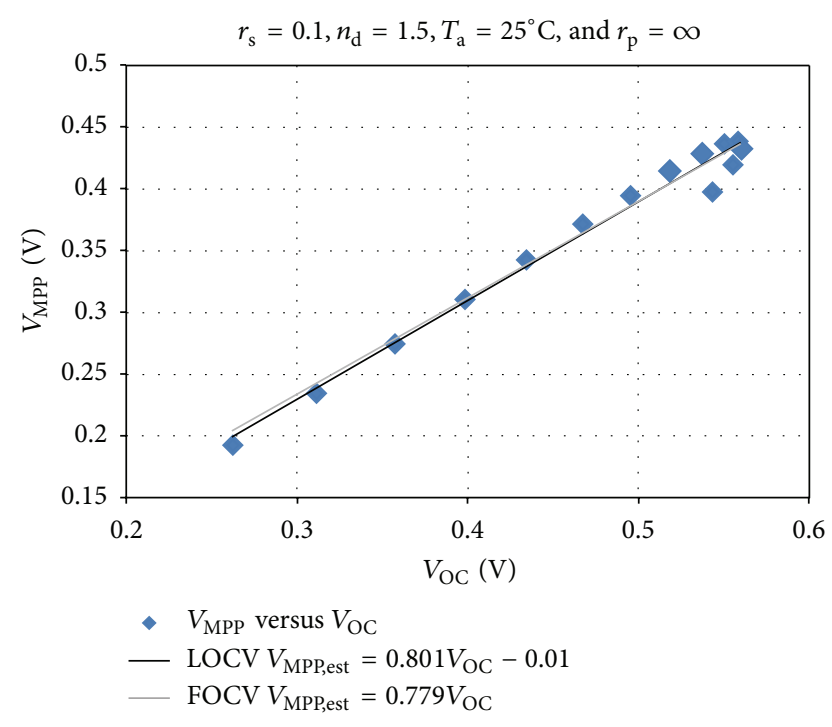

Figure 6: Computed $V_{\text {MPP }}$ versus $V_{\text {OC }}$ for a single PV cell with $T_{\mathrm{a}}=25^{\circ} \mathrm{C}, n_{\mathrm{d}}=1.5, r_{\mathrm{p}}=\infty$, and $r_{\mathrm{s}}=0.1$. Two regression lines corresponding to the FOCV and LOCV methods are also represented.

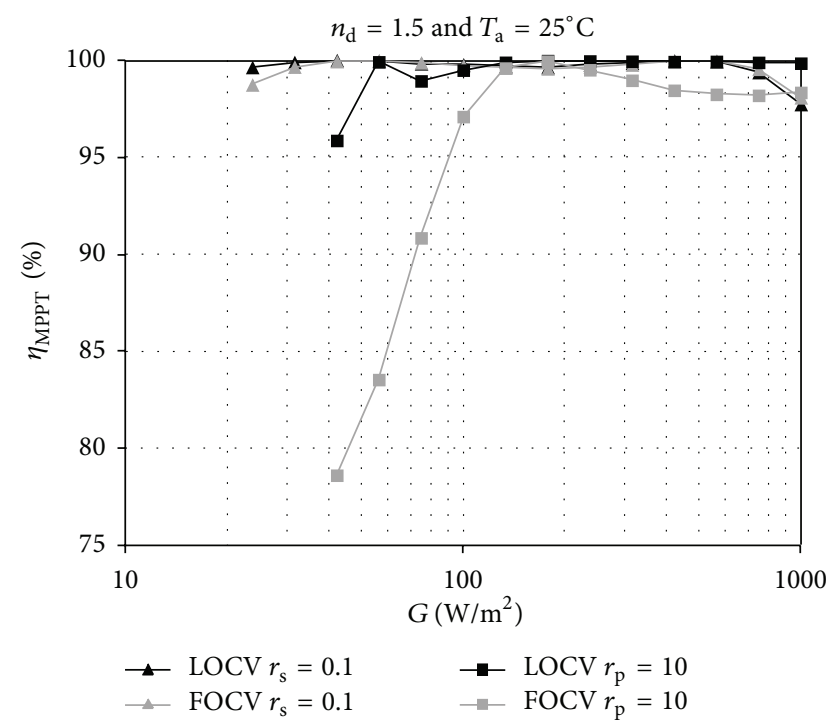

FIGURE 7: Computed $\eta_{\text {MPPT }}$ versus $G$ by using the FOCV and the LOCV methods for a single PV cell with $T_{\mathrm{a}}=25^{\circ} \mathrm{C}, n_{d}=1.5$, and for both $r_{\mathrm{s}}=0.1$ (and $r_{\mathrm{p}}=\infty$ ) and $r_{\mathrm{p}}=10$ (and $r_{\mathrm{s}}=0$ ).

remain constant by adding PV cells in series: both $V_{\text {MPP }}$ and $V_{\text {OC }}$ will scale up by the number of serial cells but their ratio will remain constant and so the derived tracking efficiencies.

\section{Experimental Results}

The LOCV method was tested with a $500 \mathrm{~mW}\left(I_{\mathrm{SC}}=160 \mathrm{~mA}\right.$, $\left.V_{\mathrm{OC}}=4.6 \mathrm{~V}\right) \mathrm{PV}$ panel (MSX-005, Solarex) and compared with the FOCV method. These low-power panels are used, for example, to power autonomous sensors [5-10]. In order

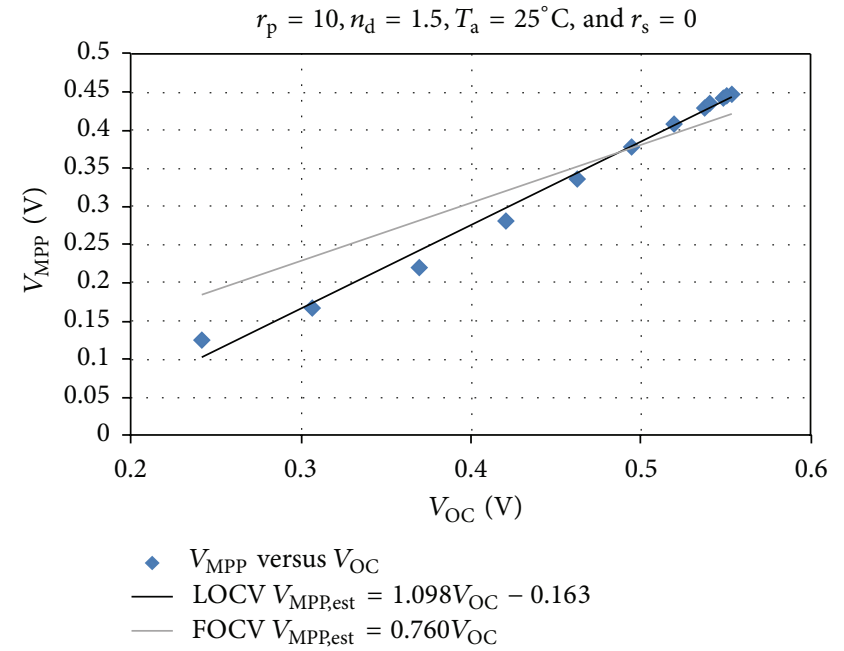

FIgURE 8: Computed $V_{\text {MPP }}$ versus $V_{\text {OC }}$ for a single PV cell with $T_{\mathrm{a}}=25^{\circ} \mathrm{C}, n_{\mathrm{d}}=1.5, r_{\mathrm{s}}=0$, and $r_{\mathrm{p}}=10$. Two regression lines corresponding to the FOCV and LOCV methods are also represented.

to achieve reproducible results, we implemented a PV panel simulator by connecting a current source (GS610, Yokogawa) in parallel with the PV panel, which was coated with an opaque cover (Figure 9). In this way, the short circuit current $\left(I_{\mathrm{SC}}\right)$ of the PV panel was adjusted by the current source, emulating different levels of irradiance. Since the panel was not illuminated, $T_{\text {celL,NOCT }}=20^{\circ} \mathrm{C}$ (i.e., the panel is not overheated). The current source was configured to cover the full range of the PV panel, varying from $5 \mathrm{~mA}$ to $158 \mathrm{~mA}$ in $9 \mathrm{~mA}$ steps. The PV panel simulator was characterized by using the GS610's measurement unit to measure the panel's voltage, a 2001 multimeter (Keithley) to measure the current of the panel, and a programmable voltage source (Agilent E3631A) in parallel with a $10 \Omega / 1 \mathrm{~W}$ resistor acting as a load. Figure 9 shows the experimental setup.

All the instruments were controlled via the GPIB bus with a dedicated program using the graphical development environment LabVIEW. For each current value $\left(I_{\mathrm{SC}}\right)$, the voltage of the E3631A was increased from $0 \mathrm{~V}$ to $5 \mathrm{~V}$ in $0.1 \mathrm{~V}$ steps. PV output voltages and currents were measured and the corresponding power values were calculated in order to obtain the $I-V$ and $P-V$ curves. From each $P-V$ curve the values of $V_{\mathrm{OC}}, V_{\mathrm{MPP}}$, and $P_{\mathrm{MPP}}$ were obtained. The limit values for $P_{\mathrm{MPP}}$ were, respectively, $8.2 \mathrm{~mW}\left(I_{\mathrm{SC}}=5 \mathrm{~mA}\right)$ and $545.9 \mathrm{~mW}$ $\left(I_{\mathrm{SC}}=158 \mathrm{~mA}\right)$.

Figure 10 represents the experimental data of $V_{\text {MPP }}$ versus $V_{\mathrm{OC}}$ and two fitted least-squares regression lines corresponding to the FOCV and LOCV methods. As can be seen, the regression line corresponding to the LOCV method better fits the experimental data. From the two regression lines, the values of $V_{\mathrm{MPP} \text {,est }}$ corresponding to the FOCV and LOCV methods were derived. Then, from the $P-V$ curves, the values of $P_{\text {MPP,est }}$ and $\eta_{\text {MPPT }}$ were obtained. Figure 11 shows $\eta_{\text {MPPT }}$ versus $P_{\text {MPP }}$. In agreement with the computed results of Section 3, the LOCV method clearly outperformed the 


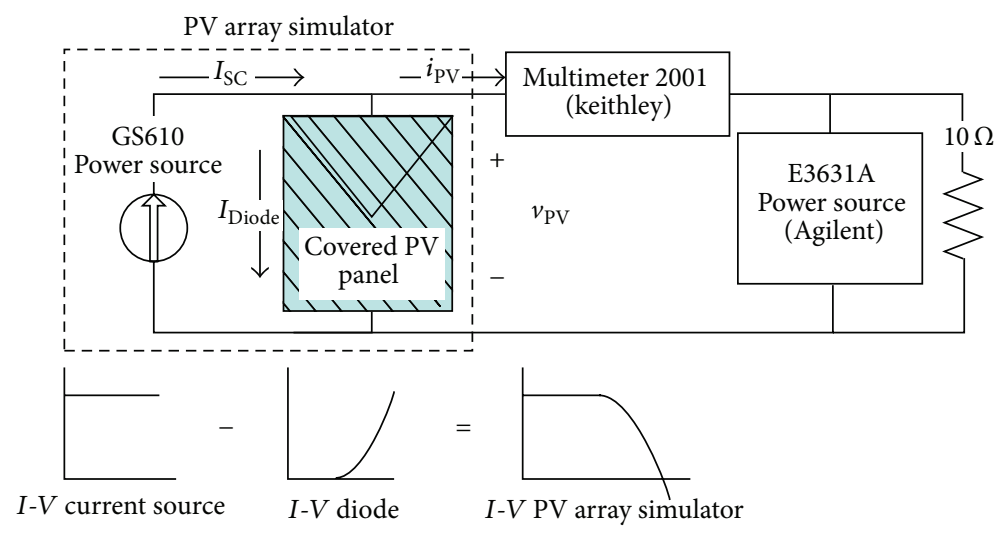

FIgURE 9: The PV array simulator and the setup used for its characterization.

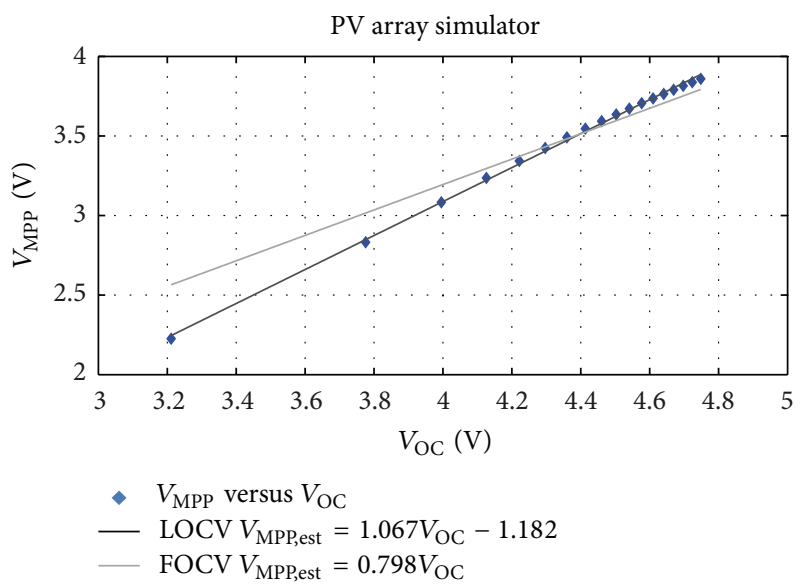

FIgURE 10: $V_{\text {MPP }}$ versus $V_{\text {OC }}$ for a $500 \mathrm{~mW}$ panel simulator at $T_{\mathrm{a}}=$ $25^{\circ} \mathrm{C}$ and two fitted least-square regression lines corresponding to the FOCV and LOCV methods.

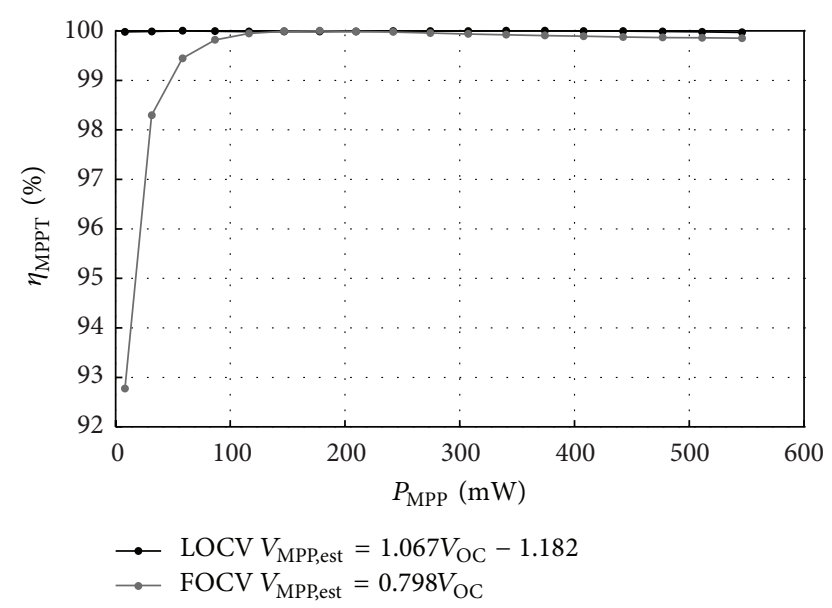

FIgURE 11: Experimental $\eta_{\text {MPPT }}$ versus $P_{\text {MPP }}$ by using the FOCV method (grey line), with $k=0.798$, and the LOCV method (black line), with $a=1.0674$ and $b=-1.182$, for a $500 \mathrm{~mW}$ PV panel.
FOCV method at low irradiance, with $\eta_{\text {MPPT }}$ always being higher than $99.96 \%$. The efficiency increase at low irradiance is of significant importance in order to power sensor nodes.

\section{Conclusion}

PV cells have been proposed in the literature in order to power the sensor nodes of WSN. Because of the limited computing capabilities of the sensor nodes, simple MPPT methods have to be used. Among them, the FOCV method has been widely proposed and used. Tracking efficiencies, though, are lower than that achieved with more complex methods. In this work, we have proposed the LOCV method, which outperforms the FOCV method while maintaining its inherent simplicity. Computations show that the LOCV method achieves a high efficiency for all the irradiance range whereas the FOCV method fails in achieving a high efficiency at low irradiance levels for most of the cases. The presence of extremely low values of shunt resistance of the PV cell negatively impacts the achieved efficiency on both methods but specially that of the FOCV method. Finally, experimental data from a low-power $500 \mathrm{~mW}$ PV panel confirmed the good performance of the LOCV method for a wide range of irradiance, which is of significant value for powering sensor nodes.

\section{Conflict of Interests}

The authors declare that there is no conflict of interests regarding the publication of this paper.

\section{Acknowledgment}

This work was supported by the Spanish Ministry of Economy and Competitiveness under Contract TEC2011-27397.

\section{References}

[1] T. Esram and P. L. Chapman, "Comparison of photovoltaic array maximum power point tracking techniques," IEEE Transactions on Energy Conversion, vol. 22, no. 2, pp. 439-449, 2007. 
[2] N. Onat, "Recent developments in maximum power point tracking technologies for photovoltaic systems," International Journal of Photoenergy, vol. 2010, Article ID 245316, 11 pages, 2010.

[3] D. P. Hohm and M. E. Ropp, "Comparative study of maximum power point tracking algorithms," Progress in Photovoltaics: Research and Applications, vol. 11, no. 1, pp. 47-62, 2003.

[4] V. Salas, E. Olías, A. Barrado, and A. Lázaro, "Review of the maximum power point tracking algorithms for stand-alone photovoltaic systems," Solar Energy Materials and Solar Cells, vol. 90, no. 11, pp. 1555-1578, 2006.

[5] D. Dondi, A. Bertacchini, D. Brunelli, L. Larcher, and L. Benini, "Modeling and optimization of a solar energy harvester system for self-powered wireless sensor networks," IEEE Transactions on Industrial Electronics, vol. 55, no. 7, pp. 2759-2766, 2008.

[6] A. S. Weddell, G. V. Merrett, and B. M. Al-Hashimi, "Photovoltaic sample-and-hold circuit enabling MPPT indoors for low-power systems," IEEE Transactions on Circuits and Systems I, vol. 59, no. 6, pp. 1196-1204, 2012.

[7] A. Chini and F. Soci, "Boost-converter-based solar harvester for low power applications," Electronics Letters, vol. 46, no. 4, pp. 296-298, 2010.

[8] F. I. Simjee and P. H. Chou, "Efficient charging of supercapacitors for extended lifetime of wireless sensor nodes," IEEE Transactions on Power Electronics, vol. 23, no. 3, pp. 1526-1536, 2008.

[9] O. Lopez-Lapeña and M. T. Penella, "Low-power FOCV MPPT controller with automatic adjustment of the sample\&hold," Electronics Letters, vol. 48, no. 20, pp. 1301-1303, 2012.

[10] M. T. Penella and M. Gasulla, "Optical energy harvesting," in Powering Autonomous Sensors, chapter 5, section 5.5, pp. 101107, Springer, Dordrecht, The Netherlands, 2011.

[11] J. A. Gow and C. D. Manning, "Development of a photovoltaic array model for use in power-electronics simulation studies," IEE Proceedings: Electric Power Applications, vol. 146, no. 2, pp. 193-200, 1999.

[12] M. G. Villalva, J. R. Gazoli, and E. R. Filho, "Comprehensive approach to modeling and simulation of photovoltaic arrays," IEEE Transactions on Power Electronics, vol. 24, no. 5, pp. 11981208, 2009.

[13] C. Carrero, J. Amador, and S. Arnaltes, "A single procedure for helping PV designers to select silicon PV modules and evaluate the loss resistances," Renewable Energy, vol. 32, no. 15, pp. 25792589, 2007.

[14] W. de Soto, S. A. Klein, and W. A. Beckman, "Improvement and validation of a model for photovoltaic array performance," Solar Energy, vol. 80, no. 1, pp. 78-88, 2006.

[15] F. Adamo, F. Attivissimo, A. Di Nisio, and M. Spadavecchia, "Characterization and testing of a tool for photovoltaic panel modeling," IEEE Transactions on Instrumentation and Measurement, vol. 60, no. 5, pp. 1613-1622, 2011.

[16] F. Lasnier and T. G. Ang, Photovoltaic Engineering Handbook, Adam Hilger, New York, NY, USA, 1990.

[17] A. Luque and S. Hegedus, Handbook of Photovoltaic Science and Engineering, 2003. 

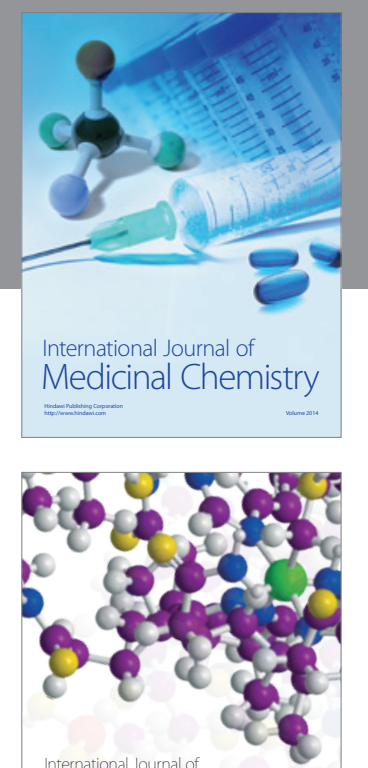

\section{Carbohydrate} Chemistry

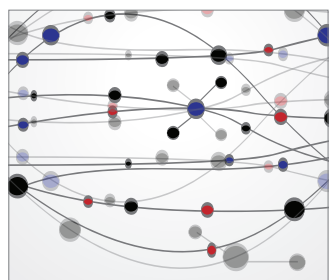

The Scientific World Journal
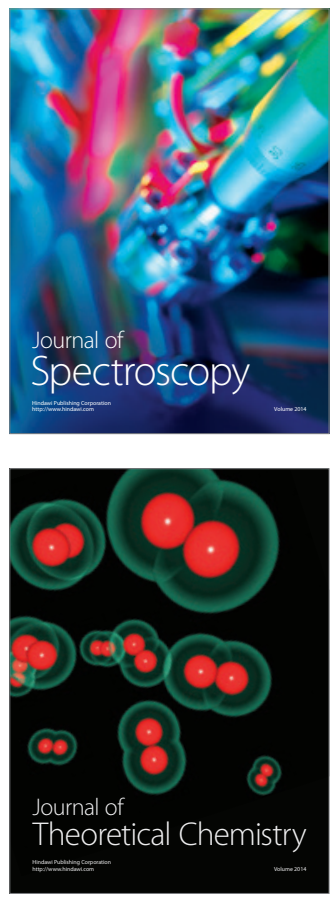
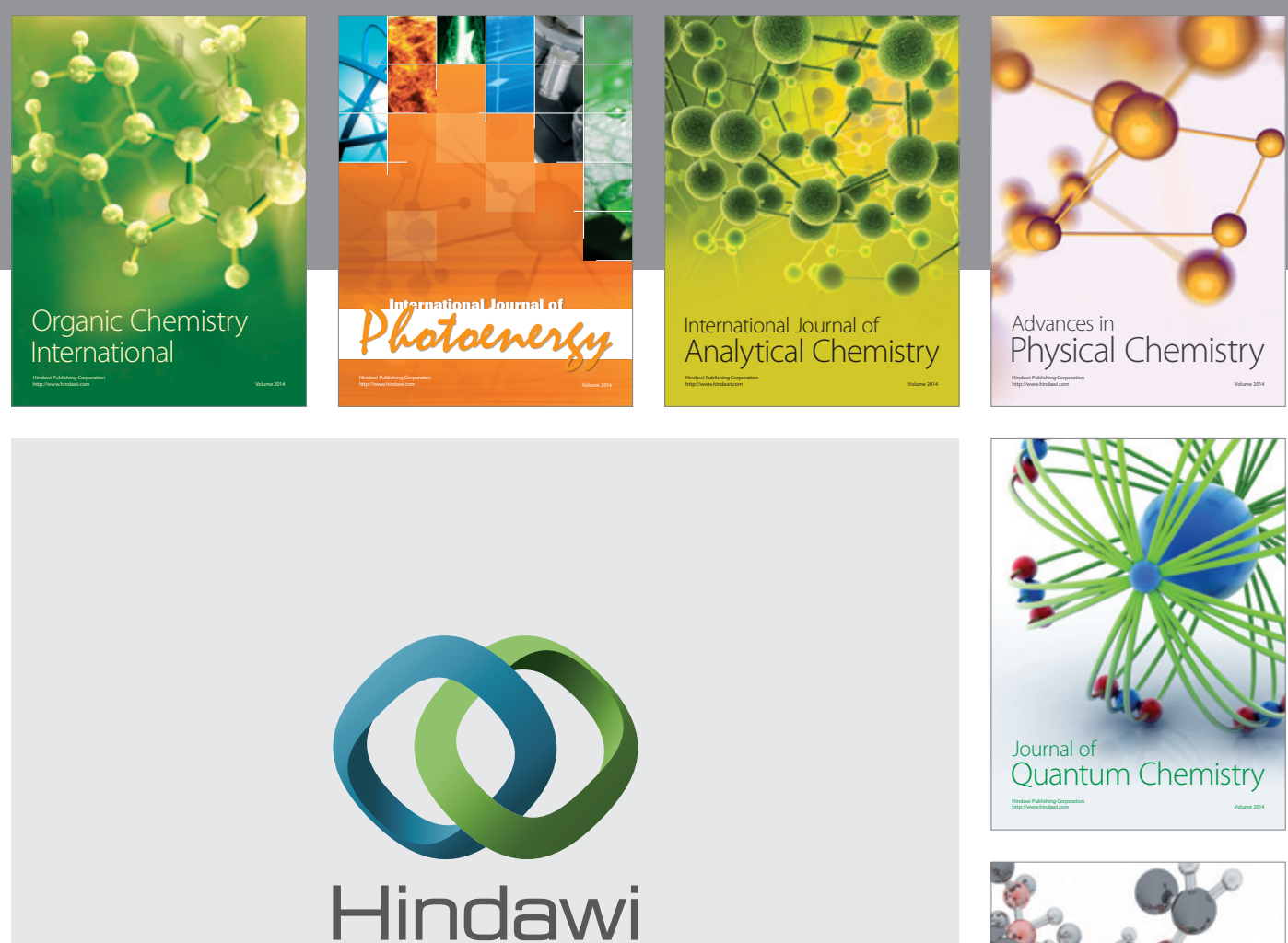

Submit your manuscripts at

http://www.hindawi.com

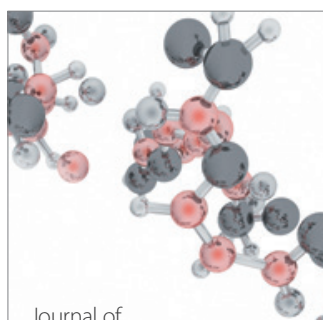

Analytical Methods

in Chemistry

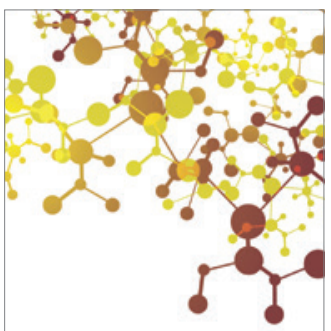

Journal of

Applied Chemistry

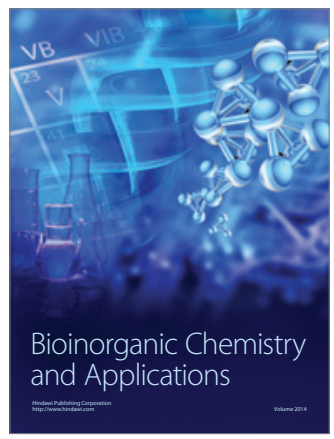

Inorganic Chemistry
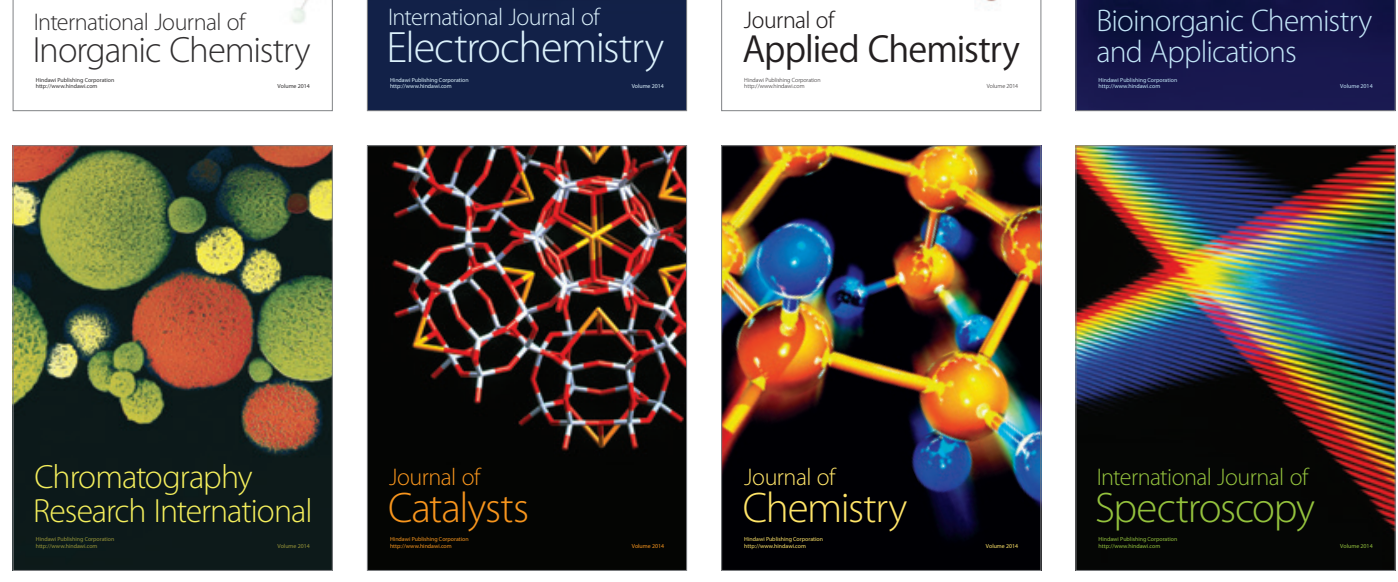